\title{
Nervous System Injury
}

National Cancer Institute

\section{Source}

National Cancer Institute. Nervous System Injury. NCI Thesaurus. Code C4974.

Injury in the central or peripheral nervous system. 